Article

\title{
Changes of Reference Evapotranspiration and Its Relationship to Dry/Wet Conditions Based on the Aridity Index in the Songnen Grassland, Northeast China
}

\author{
Qiyun Ma ${ }^{1}$, Jiquan Zhang ${ }^{1, *}$, Caiyun Sun ${ }^{1}$, Enliang Guo ${ }^{1}$, Feng Zhang ${ }^{1}$ and Mengmeng Wang ${ }^{2}$ \\ 1 Institute of Natural Disaster Research, School of Environment, Northeast Normal University, \\ Changchun 130024, China; maqy315@nenu.edu.cn (Q.M.); xlsdydnl@126.com (C.S.); \\ guoel675@nenu.edu.cn (E.G.); zhangf093@nenu.edu.cn (F.Z.) \\ 2 College of Resources and Environment, Northeast Agricultural University, Harbin 150030, China; \\ shinegarden121@163.com \\ * Correspondence: zhangjq022@nenu.edu.cn; Tel.: +86-135-9608-6467
}

Academic Editor: Franco Salerno

Received: 22 February 2017; Accepted: 26 April 2017; Published: 29 April 2017

\begin{abstract}
Reference evapotranspiration $\left(E T_{0}\right)$ plays an important role in regional dry/wet conditions. Based on the Food and Agriculture Organization of the United (FAO) Penman-Monteith method and daily climate variables, $E T_{0}$ was calculated for 21 stations in and around the Songnen Grassland, northeast China, during 1960-2014. The temporal and spatial variations of $E T_{0}$ and precipitation $(P)$ were analyzed in the annual, seasonal, and growing season (from April to October) time series using the Mann-Kendall test, Sen's slope estimator, and linear regression coupled with a break trend analysis. A sensitivity analysis was used to detect the key climate parameter contributing to $E T_{0}$ change. By linear regression analysis on the relationship between $E T_{0}, P$, and the aridity index $(A I)$, the role of $E T_{0}$ in determining regional wet/dry conditions was analyzed. Results show a higher $E T_{0}$ in the southwest and a lower $E T_{0}$ in the northeast, but $P$ was opposite to that of $E T_{0}$. Evident decreasing trends of $E T_{0}$ in the annual, seasonal, and growing season time series were detected in almost the entire region by the trend analysis methods. For the entire region, the decreasing trend of $E T_{0}$ can be linked to the relative humidity and maximum air temperature. The positive contribution of increasing temperature to $E T_{0}$ was offset by the effect of the significantly decreasing relative humidity, wind speed, and sunshine duration at the 0.05 level during 1960-2014. In addition, the value of $E T_{0}$ was higher in drought years and lower in wet years.
\end{abstract}

Keywords: reference evapotranspiration; climatic change; drought/wet; Songnen Grassland

\section{Introduction}

Climate change is an indisputable fact and may accelerate hydrological cycles and redistribute global water resources [1,2]. The change has been identified not only in individual parameters, such as temperature or precipitation, but also in integrated parameters, like reference evapotranspiration $\left(E T_{0}\right)$ [3]. $E T_{0}$ is one of the vital components of the hydrological cycle and controls the energy and mass exchange between terrestrial ecosystems and the atmosphere [3,4]. It is influenced by many factors including climate factors (e.g., temperature, solar radiation), crop factors (e.g., crop pattern, cropping system), environmental conditions, and water resource management [5]. Changes in $E T_{0}$ affect agricultural production, water resource programming, and irrigation systems. The observation of trends in these climate factors can reveal the possible impacts of climate change or climate natural variability on the hydrological cycle, identify the spatial and temporal variation, and determine the 
dominant climatic variables affecting $E T_{0}$. These trends can be helpful in determining appropriate measures for mitigating the potential damage from climate change or its natural variability effects [6-8]. However, the relationship between changing $E T_{0}$ and the dry/wet tendency is not quite clear, though it is crucial for water resource management.

Studies that investigate changes in climate factors have yielded a mixture of results and conclusions about the trends of $E T_{0}$ for specific locations during the last few decades. Contrary to the general expectation that an increase in temperature leads to an increase in evapotranspiration, such as in south and southeast Romanian during 1961-2007 and in the semi-arid and humid regions in Iran during 1966-2005 [3,9], some previous studies conclude that evaporation has diminished in the last few decades. In the upper and middle to lower Yangtze River basin, Wang et al. [10] reported a decreasing trend in $E T_{0}$ from 1961-2000 based on daily data from 115 meteorological stations. Over a 116-year period (1983-2008), Irmak et al. [11] found a significant decrease in $E T_{0}$ in the Platte river basin, USA. The same declining trends were also found in other regions throughout the world, such as New Zealand (from the 1970s to the early 2000s), India (1971-2002), and parts of China (1960-2010) [12-14]. However, an increasing trend in $E T_{0}$ was identified in other regions from the 1960s to early 2000s, such as Iran (1965-2005), Northern Eurasia (1948-2005), and parts of Romania (1961-2007) [3,15,16].

Being a typical farming-pastoral ecotone located in the central part of northeast China, the Songnen Grasslands have experienced high spatial and temporal variability in $E T_{0}$ and precipitation. This makes the management of water resources difficult in the region. However, to the best of our knowledge, there has been no comprehensive study of the relationships between changes in $E T_{0}$ and dry/wet conditions, and especially, the sensitivity of $E T_{0}$ to climatic variables in this region. Water is the lifeline for socioeconomic development in the Songnen Grassland, because agriculture and animal husbandry, which heavily depend on precipitation and irrigation, are the main industries in the area. Therefore, understanding $E T_{0}$ trends and their role in regional dry/wet conditions could give a scientific basis for regional water resource management and allocation and for the scientific decision-making of preventing flood and drought disaster.

To address the problem of the unclear $E T_{0}$ changes in the Songnen Grassland, this study set the following objectives: (1) to evaluate the spatial distribution of the $E T_{0}$ and precipitation at the annual, seasonal, and growing season time scales in the Songnen Grassland over the period from 1960-2014; (2) to investigate the temporal trend of $E T_{0}$ by using the Mann-Kendall test, and linear regression coupled with a break trend analysis, and the slopes of trend lines using the Sen's slope estimator; (3) to analyze temporal trends in the climatic parameters needed to calculate $E T_{0}$ and the sensitivity and trends of $E T_{0}$ related to the climatic parameters using the sensitivity analysis method; and (4) to explore the role of changing $E T_{0}$ in regional dry or wet conditions based on the aridity index $(A I)$. The results of this study will improve our understanding of the impact of climate change or climate natural variability on regional hydrological processes and agricultural irrigation management.

\section{Materials and Methods}

\subsection{Study Area}

The Songnen Grassland is located in central northeast China. It lies from $43^{\circ} 30^{\prime} \mathrm{N}$ to $48^{\circ} 05^{\prime} \mathrm{N}$ and from $122^{\circ} 12^{\prime} \mathrm{E}$ to $126^{\circ} 20^{\prime} \mathrm{E}$, and covers an area of approximately $22,350 \mathrm{~km}^{2}$ (Figure 1). Generally, the study area is located in the meadow steppe belt of China and is an important grassland in the Eurasian steppe zone. The region is dominated by a temperate continental monsoon climate, with four distinct seasons: quite dry (drought in nine years out of ten), windy springs; warm, rainy summers; sunny, mild autumns; and long, freezing, and dry winters [17,18]. From 1960 to 2014, the mean annual temperature ranged from $1.9^{\circ} \mathrm{C}$ in the southwest to $6.2^{\circ} \mathrm{C}$ in the northeast, while the mean annual precipitation amount varied from $350 \mathrm{~mm}$ in the southwest to $500 \mathrm{~mm}$ in the northeast. Meanwhile, the mean annual amount of evaporation is roughly two or three times the precipitation. 


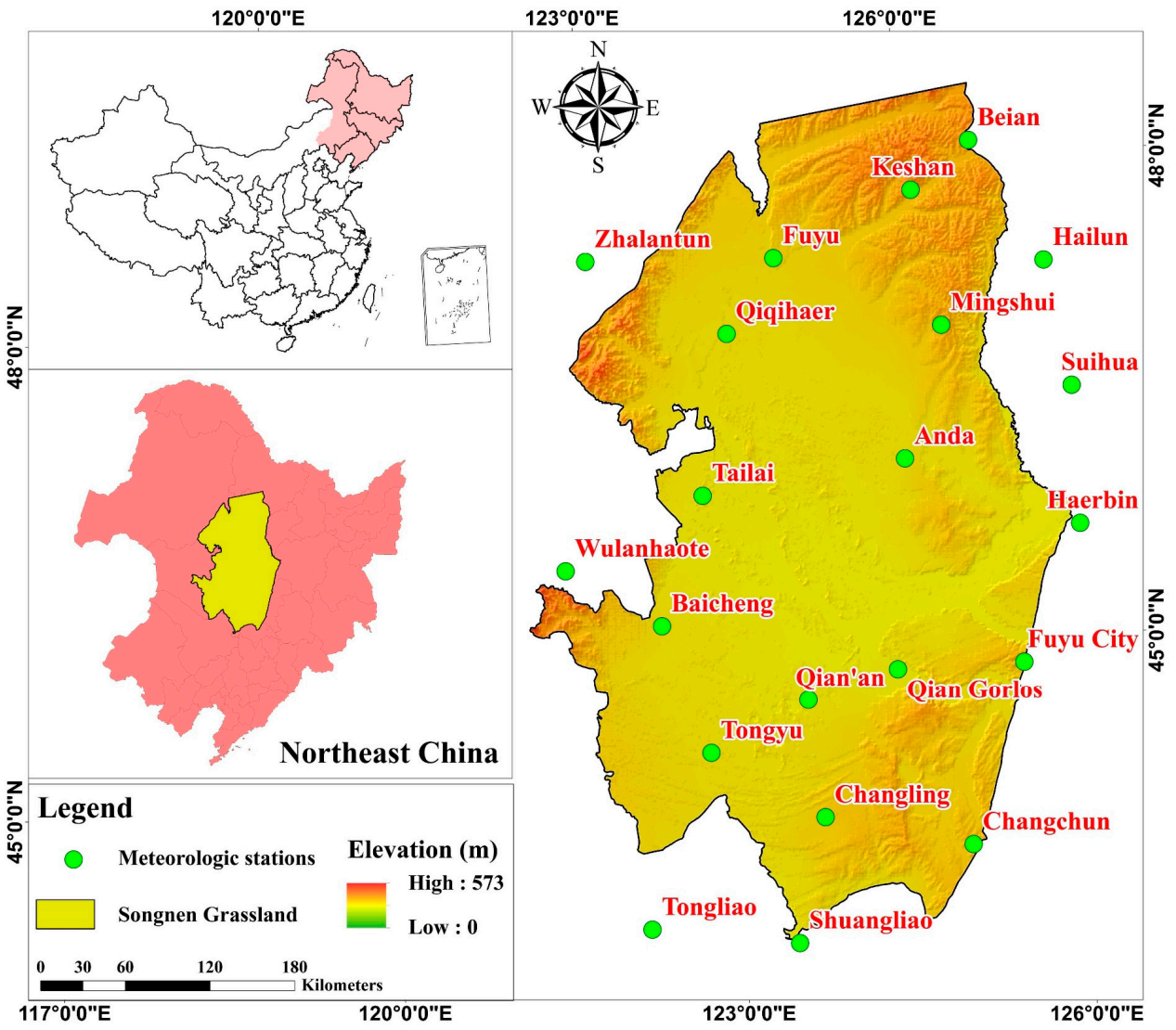

Figure 1. Location of the Songnen Grassland in China and the meteorological stations considered.

The Songnen Grassland forms a typical agricultural area in the east and an agro-pastoral transition zone in the west, determined by various physical geographical features and regional climatic differences [17]. The current ecological environment tends to be deteriorating (e.g., grassland degradation, desertification, and alkalization) due to recent and ongoing climate change and land use change in the region. Since agriculture and animal husbandry development are the main priorities within the general economic strategy of the region, an investigation of changes in $E T_{0}$ and its role in regional dry/wet conditions are needed for agriculture managers and stakeholders.

\subsection{Climate Data and Quality Control}

Climate data from 21 meteorological observatory stations were provided by the National Meteorological Information Centre of China, including daily observations of maximum air temperature (Max $T,{ }^{\circ} \mathrm{C}$ ), minimum air temperature (Min $T,{ }^{\circ} \mathrm{C}$ ), average air temperature (Ave $T,{ }^{\circ} \mathrm{C}$ ), average relative humidity (Ave $R H, \%$ ), wind speed (Win $S, \mathrm{~m} / \mathrm{s}$ ), sunshine duration (Sun $H, \mathrm{~h}$ ), and precipitation $(P, \mathrm{~mm})$, for the period from 1960-2014. The regional values for the seasonal, growing season (from April to October), and annual climatic variables were then calculated by the weighted average or sum method. The weight of every station was obtained by the Thiessen polygon method, which assigns the weight in accordance with the areas of each station [19]. Thermal seasons were considered as winter (December, January, and February), spring (March, April, and May), summer (June, July, and August), and autumn (September, October, and November).

The location of the chosen meteorological stations is shown in Figure 1. They are all distributed inside or adjacent to the study area in order to cover the entire region. All selected stations have good-quality data and meet the QA (Quality assurance)/QC (Quality control) requirements, which means that the spatial distribution of the stations had to cover the entire region, the time series had to be long enough to obtain statistically significant results in trend analyses, and the climate data was 
quality controlled by the China Meteorological Administration (http://cdc.cma.gov.cn). The missing data were substituted with the corresponding long-term mean value. Although the infilling of missing data may have a slight influence on the trend analysis for each climatic variable and the computation of $E T_{0}$, the effect may be negligible since the missing data are infrequent and account for only $0.05-0.1 \%$ of the data.

\subsection{Methods}

\subsubsection{Calculation of Reference Evapotranspiration $\left(E T_{0}\right)$}

The FAO-56 Penman-Monteith (FAO-PM) equation was recommended as the sole and global standard method for $E T_{0}$ calculation [5,20]. The method has been widely verified for its accuracy and reliability in various climatologic zones around the world [21,22]. Accordingly, the FAO-PM method was used to estimate the daily $E T_{0}$ in this study; and, subsequently the seasonal, growing season, and annual $E T_{0}$ values were derived from the daily values. The FAO-PM equation is expressed as:

$$
E T_{0}=\frac{0.408 \Delta\left(R_{n}-G\right)+\gamma \frac{900}{(T+273)} U_{2}\left(e_{s}-e_{a}\right)}{\Delta+\gamma\left(1+0.34 U_{2}\right)}
$$

where $E T_{0}$ is the reference evapotranspiration $(\mathrm{mm} / \mathrm{d}), \Delta$ is the slope of the saturation vapor pressure curve at a given air temperature $\left(\mathrm{kPa} /{ }^{\circ} \mathrm{C}\right), R_{n}$ is the net radiation at the crop surface $\left(\mathrm{MJ} /\left(\mathrm{m}^{2} \cdot \mathrm{d}\right)\right)$, $\mathrm{G}$ is the soil heat flux density $\left(\mathrm{MJ} /\left(\mathrm{m}^{2} \cdot \mathrm{d}\right)\right), \gamma$ is the psychrometric constant $\left(\mathrm{kPa} /{ }^{\circ} \mathrm{C}\right), T$ is the mean daily air temperature at $2 \mathrm{~m}$ height $\left({ }^{\circ} \mathrm{C}\right), U_{2}$ is the wind speed at $2 \mathrm{~m}$ height $(\mathrm{m} / \mathrm{s}), e_{s}$ is the saturation vapour pressure $(\mathrm{kPa}), e_{a}$ is the actual vapour pressure $(\mathrm{kPa})$, and $\left(e_{s}-e_{a}\right)$ is the saturation vapour pressure deficit $(\mathrm{kPa})$.

$R_{n}$ is the difference between the incoming net shortwave radiation $\left(R_{n s}\right)$ and the net outgoing longwave $\left(R_{n l}\right)$ radiation. $R_{n s}$ is calculated as

$$
R_{n s}=(1-\lambda) R_{s}
$$

where $R_{s}$ is the incoming solar radiation $\left(\mathrm{MJ} /\left(\mathrm{m}^{2} \cdot \mathrm{d}\right)\right)$ and $\lambda(=0.23)$ is the albedo of the hypothetical grass reference crop (dimensionless). $R_{S}$ was estimated based on the sunshine duration record according to the calibration equation by Croitoru et al. [3].

At the same time, $R_{n l}$ is given by

$$
R_{n l}=\sigma\left[\frac{T_{\max , K}{ }^{4}+T_{\min , K^{4}}}{2}\right]\left(0.34-0.14 \sqrt{e_{a}}\right)\left(1.35 \frac{R_{s}}{R_{s o}}-0.35\right)
$$

where $\sigma$ is the Stefan-Boltzmann constant $\left(=4.903 \times 10^{9} \mathrm{MJ} /\left(\mathrm{K}^{4} \cdot \mathrm{m}^{2} \cdot \mathrm{d}\right)\right) ; T_{\max , K}$ is the maximum absolute temperature during the 24 -h period $\left(K={ }^{\circ} \mathrm{C}+273.15\right) ; T_{\min , K}$ is the minimum absolute temperature during the $24-\mathrm{h}$ period $\left(K={ }^{\circ} \mathrm{C}+273.15\right)$; and $R_{s o}$ is the clear-sky radiation $\left(\mathrm{MJ} /\left(\mathrm{m}^{2} \cdot \mathrm{d}\right)\right)$. All of the variables in Equation (1) were calculated using the standard procedure outlined by Allen et al. [20]. The monthly time series of $E T_{0}$ during 1960-2014 were obtained based on the calculation of $E T_{0}$ using the CROPWAT 8.0 software developed by FAO (http:/ / www.fao.org/landwater/databases-and-software/cropwat).

\subsubsection{Trend Analysis}

To calculate trends, six data sets, including one annual, four seasonal, and one growing season, were obtained for each meteorological station. In this study, the Mann-Kendall (MK) test, a non-parametric test recommended by the World Meteorological Organization (WMO), was used to detect trends [23-25]. The MK test has been widely used for trend detection in hydrological and climatic research since the data does not need to conform to any distribution form, and it allows the 
missing data [26,27]. In this research, the missing data were filled due to computation of the $E T_{0}$. The change points were detected based on the sequential MK test, which has been largely employed for the detection of change points in different climatic and hydrological data series [28-30]. Detailed information related to the sequential MK test can be found in studies published by Palizdan et al. [29] and Liang et al. [30]. In addition, Sen's slope estimator was used to measure the magnitude of the trend [31]. The MK test and Sen's slope estimator calculations for various time series of climate factors and $E T_{0}$ were performed using the Excel-based template MAKESENS 2.0 beta, developed by researchers at the Finnish Meteorological Institute [32].

Linear regression coupled with break trend analysis [33] was applied to calculate the temporal trends of the $E T_{0}$ series for the period from 1960-2014. This method is one of the linear trend methods, which divides a certain time series into several periods. The linear regression is used in each period for detecting the temporal trend. A break trend analysis can provide more details about a long term change pattern compared with a simple linear regression. The period for the break trend analysis was chosen as every 30 years, which was considered as the climatological normal period according to the recommendation of the WMO [34]. In this study, the climatological normal ranges were from 1960 to 1989, from 1970 to 1999, from 1980 to 2009, and from 1985 to 2014. It should be noted that in both trend analysis methods, the significance level $(\alpha)$ was set to 0.05 (one-sided $t$-test).

\subsubsection{Sensitivity Analysis}

A sensitivity analysis is a quantitative description method for the effect of the input variables on the output [35]. In the present study, it was performed to evaluate the effect of climatic variables on $E T_{0}$. Because of the different approaches used in determining $E T_{0}$, there are no standard or common procedures for carrying out the sensitivity analyses on $E T_{0}[20,36]$. This study applied the sensitivity analysis method developed from Zhan et al. [37], which has the advantages of simple procedures and evident outcomes of detecting sensitive factors. The measure $S_{x}$ is the sensitivity of the FAO-PM method to a meteorological parameter, defined as:

$$
S_{x i j}=\left|\frac{E T_{0}\langle 1.1 x i j\rangle-E T_{0}\langle 0.9 x i j\rangle}{E T_{0}\langle x i j\rangle}\right|
$$

where $x_{i}$ is a meteorological parameter needed for the calculation of $E T_{0} ; j$ is a given year; $E T_{0}\left\langle x_{i j}\right\rangle, E T_{0}\left\langle 1.1 x_{i j}\right\rangle$, and $E T_{0}\left\langle 0.9 x_{i j}\right\rangle$ are the estimated $E T_{0}$ in $j$ year when the parameter $x_{i}$ equals its value or is 1.1 and 0.9 times its value, respectively. The larger the $S_{x i j}$ is, the more sensitivity $x_{i}$ will have.

\subsubsection{Aridity Index ( $A I$ Index)}

Aridity is usually expressed as a comprehensive function of precipitation, temperature, and/or potential evapotranspiration, and reflects the level of meteorological drought [38]. $A I$ is defined by Thornthwaite [39], who calculated $A I$ as dividing the difference between precipitation and potential evapotranspiration by the potential evapotranspiration. This method is understood as the dearth of water availability at the surface and subsurface levels, can express the aridity degree in arid or semiarid regions, and can help to further analyze drought-wetness variations in terms of agriculture demand $[4,40]$.

In this study, following Thornthwaite [39], the $A I$ was computed as:

$$
A I=\left(E T_{0}-P\right) / E T_{0}
$$

where $E T_{0}$ is the reference evapotranspiration, and $P$ is the precipitation. If the $A I$ is equal to or close to 1 , it indicates that there is no precipitation, and aridity is the highest. In contrast, if the precipitation is equal to or higher than $E T_{0}$, the $A I$ will be equal to 0 or negative. The $A I$ values of the growing season 
at each station were calculated, and the average $A I$ in the entire Songnen Grassland was expressed by the arithmetic average from the stations in and around the region.

\subsubsection{Spatial Interpolation}

For analyzing the spatial patterns of $E T_{0}$ trends and their magnitudes, the Inverse Distance Weighting algorithm (IDW) was used, which is extensively applied for mapping the spatial extent of climatic and hydrological point data. This method is a simple deterministic interpolation, and assumes that sample values closer to the prediction location are more representative of the prediction value than sample values farther away [41]. Therefore, the closest value to the prediction location gets the greatest weight and the weight is reduced as a function of distance [29]. The power parameter $(\alpha)$, which controls the importance of the predicted location values, is the main factor affecting the result from the IDW method. The $\alpha$, a positive, real, and constant number, can change from 1 to 5 . As a higher $\alpha$ value is selected, more weight is given to the closed location. In this study, $\alpha$ was defined as 2 by following Palizdan et al. [29]. All spatial interpolations were conducted using the ArcGIS 10.2 software.

\section{Results}

\subsection{Spatial Distribution of $E T_{0}, P$, and Their Difference over the Period from 1960-2014}

The spatial distributions of $E T_{0}$ and $P$ annually, seasonally, and during the growing season from 1960 to 2014 are shown in Figure 2, and the difference between the two is displayed using the IDW interpolation as well. Figure 2 shows a strong variability and marked difference between the northeastern ranges and the southwestern region. From the visual inspection, it was observed that the spatial pattern of the high and low values of annual $E T_{0}, P$, and their difference all show similarities to the growing season and seasonal time series. The spatial pattern of $E T_{0}$ and the difference indicated higher values in the southwest and lower values in the northeast areas, but precipitation showed the opposite trend, in which the minimum value was in the west and the highest value was in the east. Generally, the $E T_{0}$ value was more than double the precipitation amounts for all time scales considered, especially for the annual values and during the growing season.

For $E T_{0}$, the average of the annual and growing season values increased from the northeast to southwest, with values less than 850 and $750 \mathrm{~mm}$, respectively, to more than 1100 and $980 \mathrm{~mm}$, respectively. Seasonally, all of the stations showed higher $E T_{0}$ in the summer, followed by spring, autumn, and winter. For $P$, the annual value and that of the growing season increased from west to east, ranging from 381 to $577 \mathrm{~mm}$ and from 352 to $511 \mathrm{~mm}$, respectively. The minimum was found in Tongyu, and the maximum was found in Changchun. Seasonally, higher amounts of precipitation were exhibited during the summer, followed by autumn, spring, and winter. The maximum difference was distributed in the southwest at all time scales (Figure 2), especially for the annual values, reaching $700-800 \mathrm{~mm}$ in the southwest. From a seasonal perspective, the maximum value of the difference occurred in the spring, ranging from 215 to $350 \mathrm{~mm}$ and was followed by summer, autumn, and winter. 


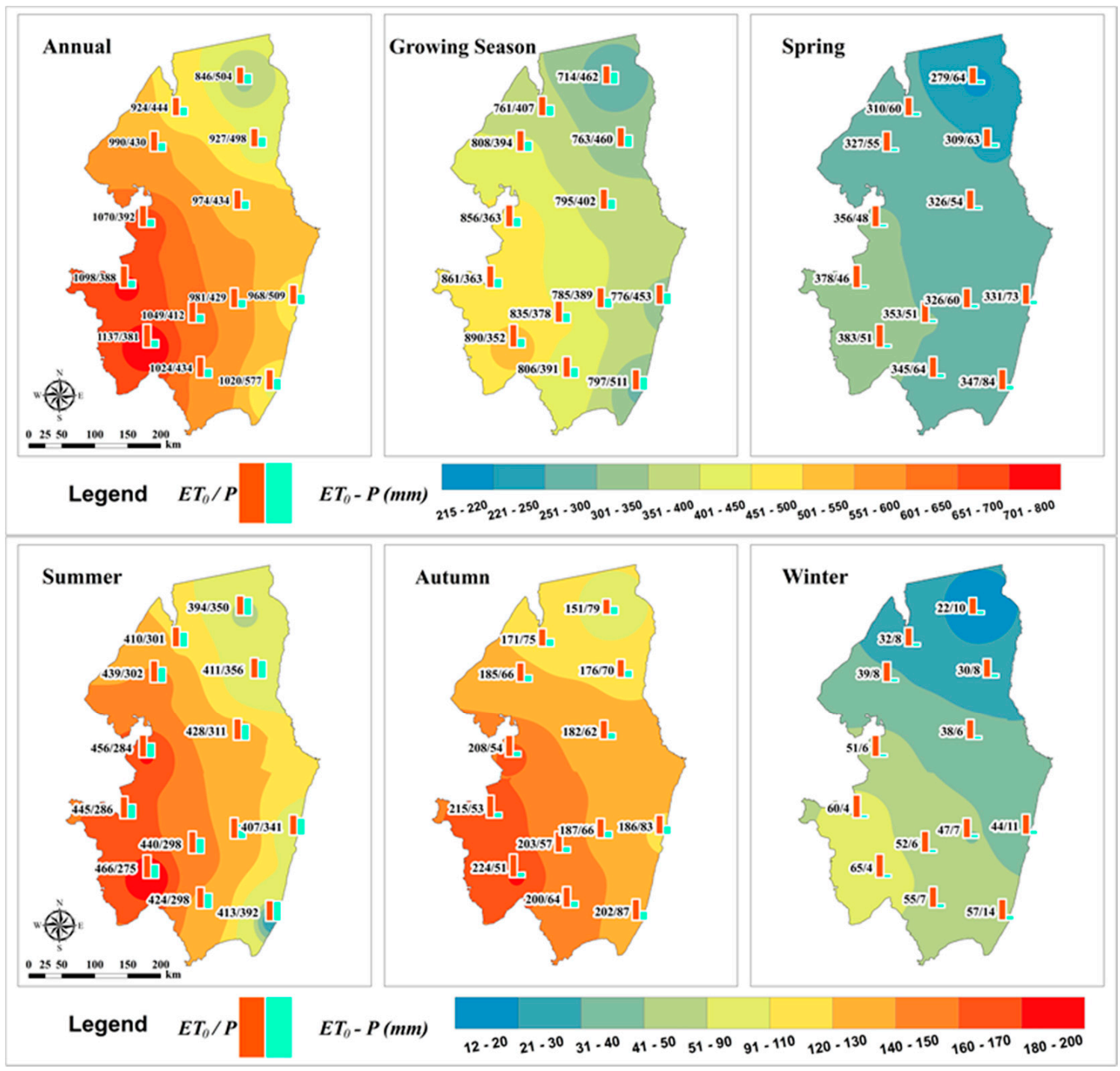

Figure 2. Spatial distribution of $E T_{0}, P$, and the difference between the two for the period from 1960-2014.

\subsection{Temporal Variations of $E T_{0}$}

The results of the break trend analysis for the area-averaged annual, seasonal, and the growing season $E T_{0}$ time series of the 21 stations during 1960-2014 are shown in Figure 3, and those of the MK test and Sen's slope estimator are summarized in Figure 4. Figure 3 indicates an evident decreasing trend in $E T_{0}$ in the annual, seasonal, and growing season time series, especially for the annual, growing season, and spring periods, which passed the significance test at the 0.05 level. In addition, it was shown that almost all annual, seasonal, and the growing season time series had experienced a decreasing trend of $E T_{0}$ for the four climatological normal time ranges with the rate ranging from -2.415 to $-0.003 \mathrm{~mm} / \mathrm{a}$. The sharpest drop rate was detected from 1970 and 1999, and the maximum was in the growing season $(-2.415 \mathrm{~mm} / \mathrm{a})$. However, it is noteworthy that the region experienced an increasing trend of $E T_{0}$ in the annual, seasonal, and the growing season time series during 1980-2009, with a rate ranging from 0.085 to $0.296 \mathrm{~mm} / \mathrm{a}$, except in spring and winter, although the increasing trend was not significant. To detect the change points, the MK test was performed in the $E T_{0}$ for the annual, seasonal, and the growing season time series during 1960-2014. As shown in Figure 3, both the annual and growing season series have three change points, 1989, 1994, and 2009, and 1989, 1995, and 2008, respectively. Seasonally, in spring, there was a clear change point in 2008; in autumn, four change points were identified, 1972, 1985, 1994, and 2009; in winter, the series had change points at 
1977 and 2011. However, there was no detectable change point in summer. The results show that abrupt changes in the $E T_{0}$ series mainly occurred in the early and mid-1990s, leading to a fluctuation of $E T_{0}$ which is dominated by a decreasing trend.
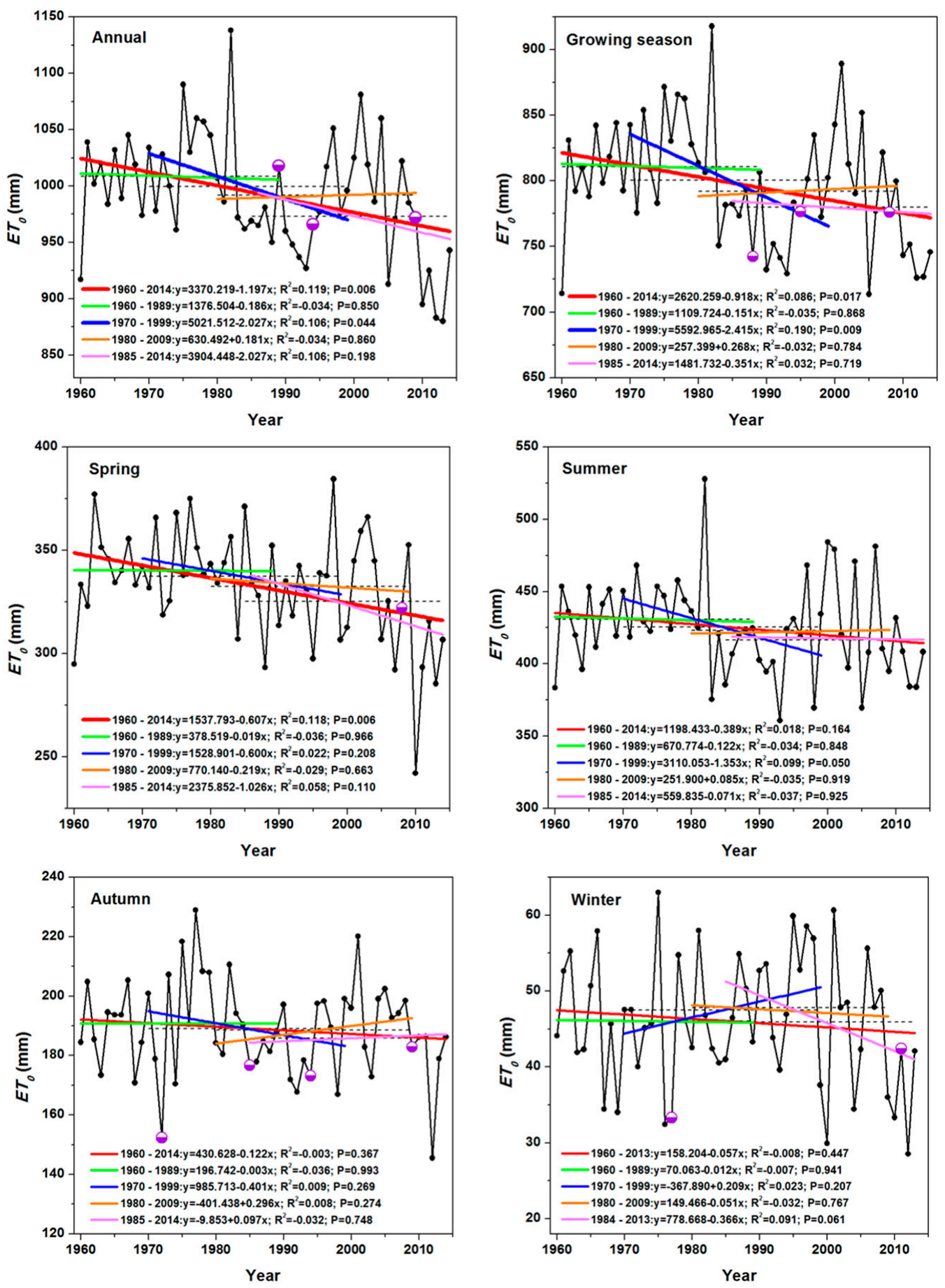

Figure 3. Linear trend and break trend analysis (for every 30 years) of $E T_{0}$ from 1960 to 2014. The black dashed line is the average value of the four climatological normal periods. $\odot$ indicates the detected change point.

The results of the MK test are exhibited in Figure 4, and they are almost identical to those from the linear trend analysis. $E T_{0}$ exhibited a decreasing trend in the annual, seasonal, and the growing season time series at the 21 stations during 1960-2014. Overall, more than 90\% of the analyzed stations 
reported decreasing trends of $E T_{0}$ except during autumn and winter, and among those stations about $50 \%$ were shown to be decreasing during the annual, growing season, and spring in a statistically significant manner. Increasing trends were found in less than $10 \%$ of the data sets, especially during autumn with $38 \%$ showing increasing trends, but none of the trends were significant. In terms of the magnitude of the trends, the highest decrease in $E T_{0}$ was recorded in Haerbin (around the region) and Fuyu City (inside the region) at the annual level, with an average decrease of -4.45 and $-2.86 \mathrm{~mm} / \mathrm{a}$, respectively. On the basis of these results, there is no doubt that the Songnen Grassland has experienced an evident decrease in $E T_{0}$ over the last 55 years. With decreasing $E T_{0}$, the crop or vegetation water demand would be reduced, and the risk of drought would be mitigated. In other words, the decrease in $E T_{0}$ rates may mitigate the drought impact on local vegetation and agricultural production.

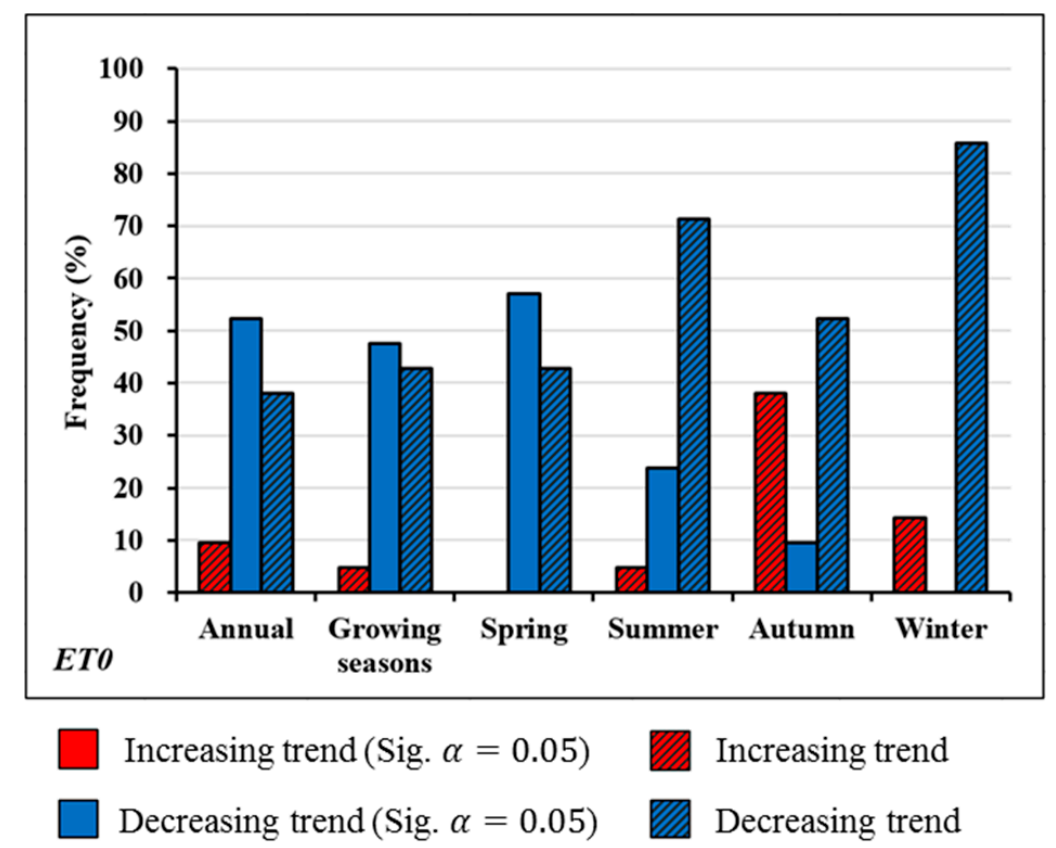

Figure 4. Frequency of $E T_{0}$ trends for the 21 stations based on the Mann-Kendall (MK) test in the Songnen Grassland during 1960-2014 (\%).

\subsection{Spatial Patterns of Trends in $E T_{0}$}

The spatial variations of $E T_{0}$ trends at different time scales from 1960 to 2014 based on the MK test are displayed in Figure 5. All considered time scales indicated a similar pattern, with the majority of the time series of $E T_{0}$ indicating a downward trend in the entire region, except during autumn. The greatest number of stations with significant decreasing trends of $E T_{0}$ were distributed in the eastern, northeastern, and central regions and frequently occurred in the annual, spring, and growing season periods. These regions also had the highest rate decrease in $E T_{0}$, ranging from -0.2 to $-4.0 \mathrm{~mm} / \mathrm{a}$. However, positive changes were recorded in the southwestern and southern regions in autumn and winter, but they were statistically insignificant, with rate increases ranging from 0.01 to $0.40 \mathrm{~mm} / \mathrm{a}$. Overall, the spatial pattern of $E T_{0}$ change in the Songnen Grassland is that of a significant downward trend across the central region with a gradually reduced intensity from the eastern parts to the western areas. 

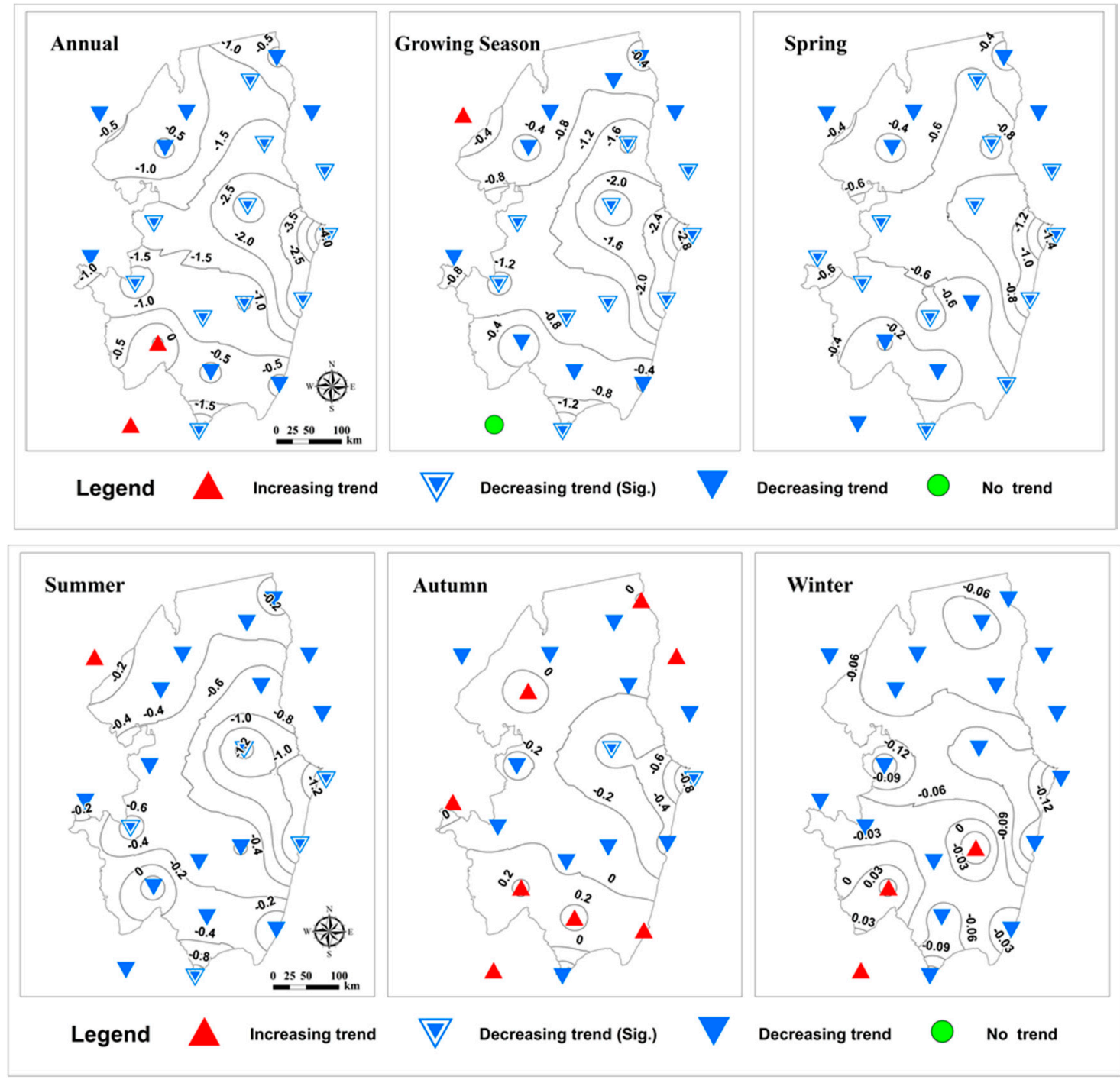

Figure 5. Spatial distribution of trends and their magnitudes in $E T_{0}$ over the period from 1960-2014. The Sig. indicates a significant trend at the 0.05 level. The black line is the contour line of the magnitude of the $E T_{0}$ trend.

\subsection{Changes in the Climatic Parameters}

The changes in basic climatic parameters that might play a considerable role in $E T_{0}$ change have been investigated for the 21 stations across the Songnen Grassland during 1960-2014. With an increase of air temperature (Ave $T$, Max $T$, and Min $T$ ), the regional annual Ave $R H$, Sun $H$, and Win $S$ all significantly decreased during the study period (Figure 6). All the climatic parameters experienced constant changes during the four climatological normal periods, i.e. from 1960 to 1989, from 1970 to 1999, from 1980 to 2009, and from 1985 to 2014. All the increasing trends of Ave T, Max T, and Min $T$ and the decreasing trends of Sun $H$ and Win $S$ passed the significance test at the 0.01 level, while the Ave $R H$ passed the significance test at the 0.05 level. The MK test was used to detect the change points for each climatic parameter. Each of them has a clear change point around 1990. The change point years of Ave T, Max T, and Min T with significant increasing trends were 1987, 1989, and 1983, respectively. Those of Ave $R H$, Win $S$, and Sun $H$ were 1993, 1990, and 1987, respectively. It is worth noting that the time of abrupt changes in Max $T$ and Ave $R H$ are almost in line with that of the annual $E T_{0}$ time series during 1960-2014. In addition, the detected change points for both the annual $E T_{0}$ and the climate parameters mainly occurred in the late 1980s and 1990s. 

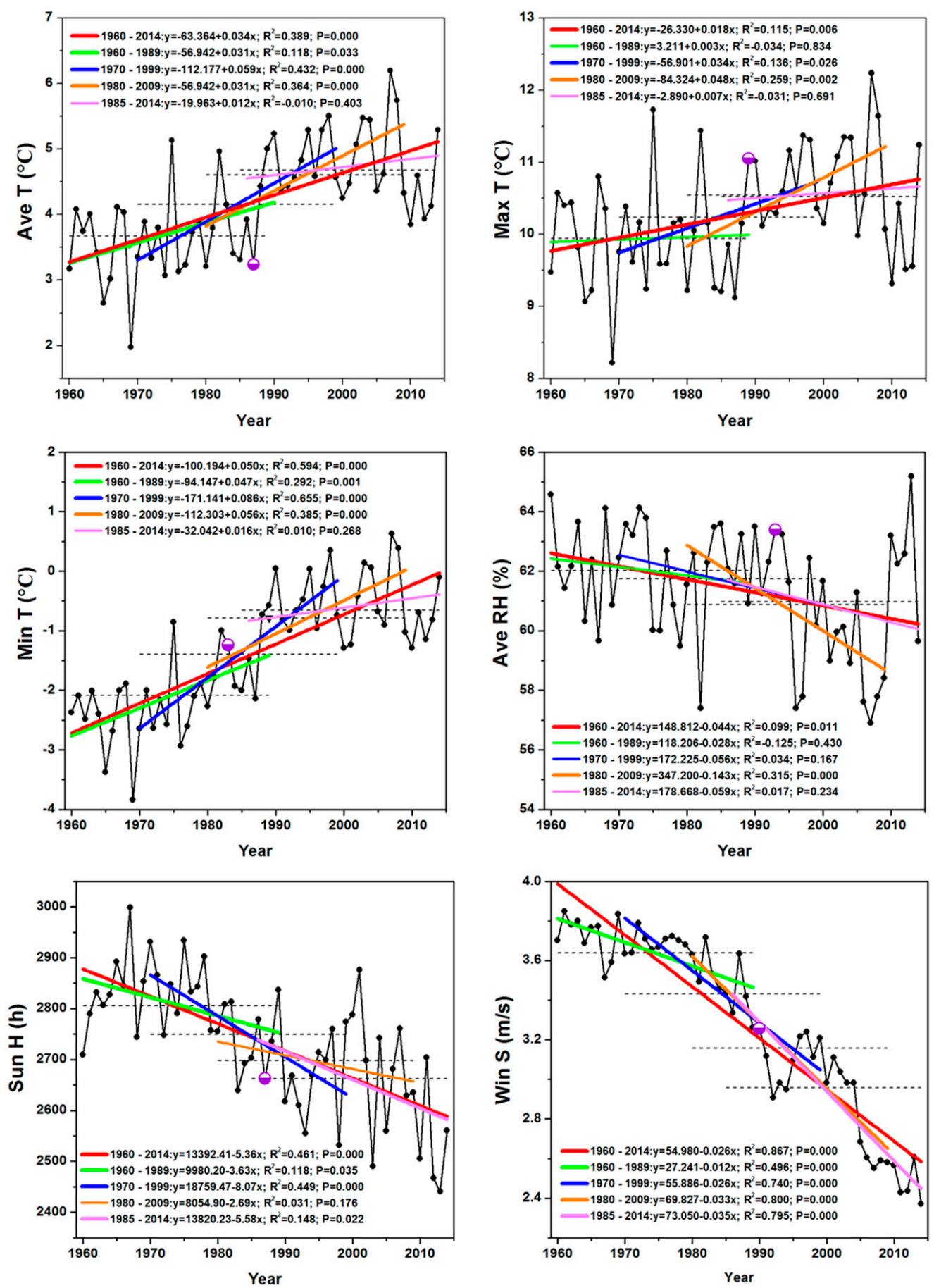

Figure 6. Linear trend and break trend analysis (for every 30 years) of the climatic parameters from 1960 to 2014 . $\bigcirc$ indicates the detected change point.

The MK test was used for detecting the statistical significance of the climatic parameters trends at the 21 stations in the annual, seasonal, and the growing season time series during 1960-2014. The results are summarized in Figure 7. For Ave $T$ and $\operatorname{Min} T$, the percentage value of the statistically significant increase $(\alpha=0.05)$ was $100 \%$ at all considered time scales, except during winter $(95 \%$ in Min $T$ and more than $70 \%$ in Ave $T$ ). In the case of Sun $H$, all of the annual, seasonal, and growing season series illustrated downward trends, ranging from $52 \%$ to $71 \%$ and being statistically significant decreases. As for Win $S$, significantly decreasing trends were found roughly $100 \%$ of the time at all 
locations. For Ave $R H$, an overwhelming majority of data series saw negative trends, but in spring, positive trends were detected at more than $50 \%$ of the stations.

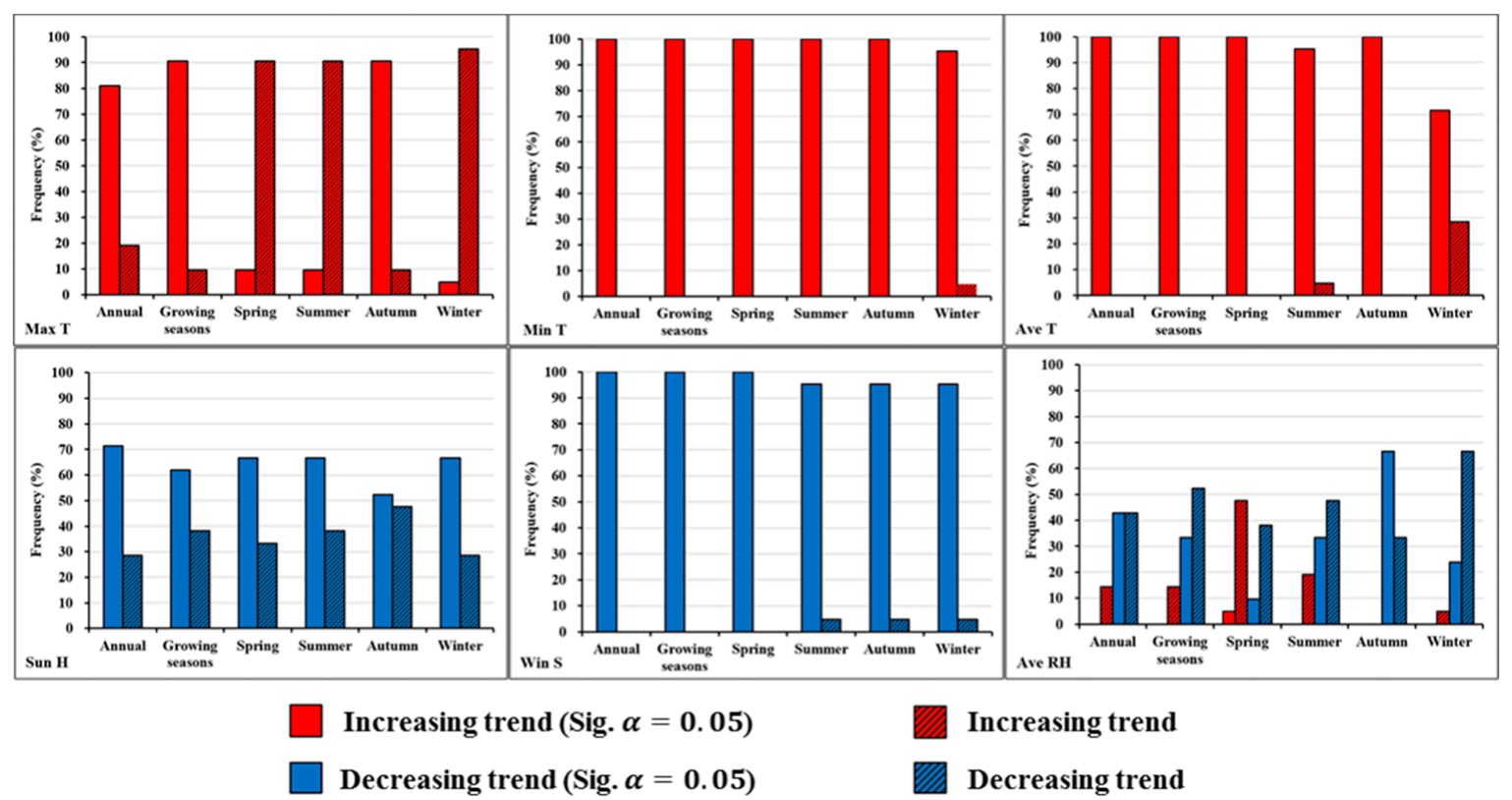

Figure 7. Frequency of climatic parameter trends in the Songnen Grassland over the period from 1960-2014 (\%).

\subsection{Sensitivity Analysis of Climatic Variables}

The results of the sensitivity analysis for annual $E T_{0}$ to the climatic variables are given in Figure 8 and Table 1 for the 13 stations inside the Songnen Grassland. It can be seen from Figure 8 that the Ave $R H$ and Max $T$ were the most sensitive variables to the change in $E T_{0}$ over the whole region, and the sensitivity decrease from $\operatorname{Win} S$, Sun $H$, Min $T$ to Ave $T$. However, there was a small difference in the northeast region at the Keshan and Mingshui stations, which may be the result of the relatively high elevation of the two stations, and there are small hills near those stations. The most sensitive climatic variables at these two stations were Ave $T$ and Min $T$, respectively. The summary of the sensitive climatic variables and the temporal trends of their sensitivities based on the MK test are given in Table 1 . The results indicate that the sensitivity of Ave $R H$ had a significant decreasing trend except at the Anda station, which had a significant increasing trend. The trend of the sensitivity of Max $T$ was the same as that of Ave $R H$ with a significant downward trend for almost the whole region, except for a significant upward trend in Changchun. For the sensitivity of Win $S$ and Min $T$, a majority of stations had a significant increasing trend. Sun $H$ had the same temporal trend as Win $S$ and Min $T$; but in the southwest region, Tongyu and Changling, there was no significant decreasing trend. As for the sensitivity of Ave $T$, the results showed a slight impact on the changing $E T_{0}$ in the Songnen Grassland, except in Keshan. To summarize, the sensitivity of Ave $R H$, Max T, Ave $T$, and Min $T$ displayed significant decreasing trends, while that of Win $S$ and Sun $H$ displayed significant increasing trends in the whole region. 
Table 1. Summary of the sensitive climatic variables that contributed to the changes in $E T_{0}$ at the stations during 1960-2014.

\begin{tabular}{|c|c|c|c|c|c|c|c|c|c|c|c|c|}
\hline $\begin{array}{l}\text { Station } \\
\text { Keshan }\end{array}$ & \multicolumn{12}{|c|}{ Order and Trend of the Sensitivity for the Climatic Variables in $\mathrm{ET}_{0}$} \\
\hline Fuyu & Ave $R H$ & $-2.38 *$ & $\operatorname{Max} T$ & $-3.17 *$ & Sun $H$ & $2.06 *$ & $\operatorname{Min} T$ & 1.56 & Win $S$ & 0.07 & Ave $T$ & 1.10 \\
\hline Qiqihaer & Ave $\mathrm{RH}$ & $-4.56^{*}$ & $\operatorname{Max} T$ & $-4.15^{*}$ & Win $S$ & 1.31 & Sun $H$ & $2.06^{*}$ & $\operatorname{Min} T$ & $4.24^{*}$ & Ave $T$ & 0.00 \\
\hline Tailai & Ave $R H$ & $-3.89 *$ & $\operatorname{Max} T$ & $-3.12 *$ & Win S & $4.02 *$ & Sun $H$ & 1.29 & $\operatorname{Min} T$ & $3.66^{*}$ & Ave $T$ & 0.00 \\
\hline Anda & Ave RH & 2.83 * & $\operatorname{Max} T$ & $-3.56 *$ & Win S & 0.20 & Sun $H$ & $4.07 *$ & $\operatorname{Min} T$ & 0.40 & Ave $T$ & 0.00 \\
\hline Baicheng & Ave RH & $-3.05 *$ & $\operatorname{Max} T$ & $-3.03 *$ & Win S & 1.19 & Sun $H$ & 1.80 & $\operatorname{Min} T$ & $2.08 *$ & Ave $T$ & 0.00 \\
\hline Tongyu & Ave RH & $-2.95 *$ & $\operatorname{Max} T$ & -1.74 & Win $S$ & $3.03 *$ & Sun $H$ & -0.15 & $\operatorname{Min} T$ & 1.06 & Ave T & 0.00 \\
\hline Changling & Ave RH & $-3.27^{*}$ & $\operatorname{Max} T$ & $-2.63^{*}$ & Win $S$ & $4.01 *$ & Sun $H$ & -1.26 & $\operatorname{Min} T$ & $2.42 *$ & Ave $T$ & 0.00 \\
\hline Fuyu City & Ave $R H$ & $-5.62 *$ & $\operatorname{Max} T$ & $-4.37 *$ & Win S & $2.42 *$ & Sun $H$ & 1.28 & $\operatorname{Min} T$ & $3.14 *$ & Ave $T$ & 0.00 \\
\hline Changchun & $\operatorname{Max} T$ & $3.11 *$ & Ave RH & $-6.11 *$ & Win S & $1.97 *$ & Sun $H$ & $3.47 *$ & $\operatorname{Min} T$ & $2.24 *$ & Ave $T$ & 0.00 \\
\hline Region & Ave $R H$ & $-4.07^{*}$ & $\operatorname{Max} T$ & $-4.18^{*}$ & Win $S$ & $2.90 *$ & Sun $H$ & $3.92 *$ & Ave T & $-6.94 *$ & $\operatorname{Min} T$ & $-7.93 *$ \\
\hline
\end{tabular}

Notes: The order means the ranking of the sensitive climatic variables (descending) at each station. The trends of the sensitivity for the climatic variables were detected by the MK test. * Indicates a significance level of 0.05 .



Figure 8. Spatial distribution of the average annual sensitivities of the climatic variables and the result of the sensitivity comparison in 13 inside stations during 1960-2014.

\subsection{The Role of $E T_{0}$ in Regional Dry/Wet Conditions}

The ratio of $E T_{0}$ during the growing season to the total annual amount was computed from 1960 to 2014. Results show that, in general, the total $E T_{0}$ in growing season accounts for more than $80 \%$ within the year. As this period is critical for crop and vegetation growth, it directly affects regional socioeconomic development. Therefore, this study only considers the role that $E T_{0}$ may play in regional dry/wet conditions during the growing season. Regional trends and the magnitudes of $E T_{0}$, $A I$, and $P$ were analyzed at two spatial scales, at the 13 inside stations and at the 21 stations which takes the adjacent stations into account, respectively. However, only the results of the 13 interior stations are presented in Figure 8, due to the similarity of the results for the analysis of the trends and the magnitudes of $E T_{0}, A I$, and $P$ at the 21 stations.

Figure 9 gives the interannual variations of the growing season $E T_{0}, A I$, and $P$ over the Songnen Grassland for the period from 1960 to 2014. From the visual inspection, $E T_{0}, A I$, and $P$ all displayed decreasing trends, but only the decreasing trend of $E T_{0}$ passed the significance test. As for the fluctuation in temporal evolution, the results indicated that the fluctuating pattern of $E T_{0}$ was similar 
to $A I$, but opposite that of $P$. A simple regression equation was established between $E T_{0}, A I$, and $P$ based on the SPSS Statistics 19.0 Software. The equation is as follows:

$$
A I=63.81-0.125 P+0.046 E T_{0}\left(R^{2}=0.98, P=0.00\right)
$$

Equation (6) indicates a positive correlation between $A I$ and $E T_{0}$ and a negative correlation between $A I$ and $P$. The regression residual standard error is displayed in Figure 10 to test the validity and accuracy of Equation (6). It indicated that the residuals are approximately normally distributed since all 55 residuals are distributed around the diagonal line, and it also illustrated that the regression equation (Equation (6)) is in line with the normal distribution. Thus, Equation (6) is statistically significant. Furthermore, the upward trends of $E T_{0}$ and $A I$ were associated with the downward trends of $P$ and vice versa. This characteristic was highly explicit during the drought and wet years in particular. As shown in Figure 10, during the severe drought years D1 (1982), D2 (2001), D3 (2004), and D4 (2007), the values of $E T_{0}$ and $A I$ had reached or were close to the maximum in the last few decades; however, the values of $P$ had almost reached a minimum at the same time. Similarly, the wet years, such as W1 (1960), W2 (1998), and W3 (2013) had lower values of $E T_{0}$ and $A I$ (Figure 9).

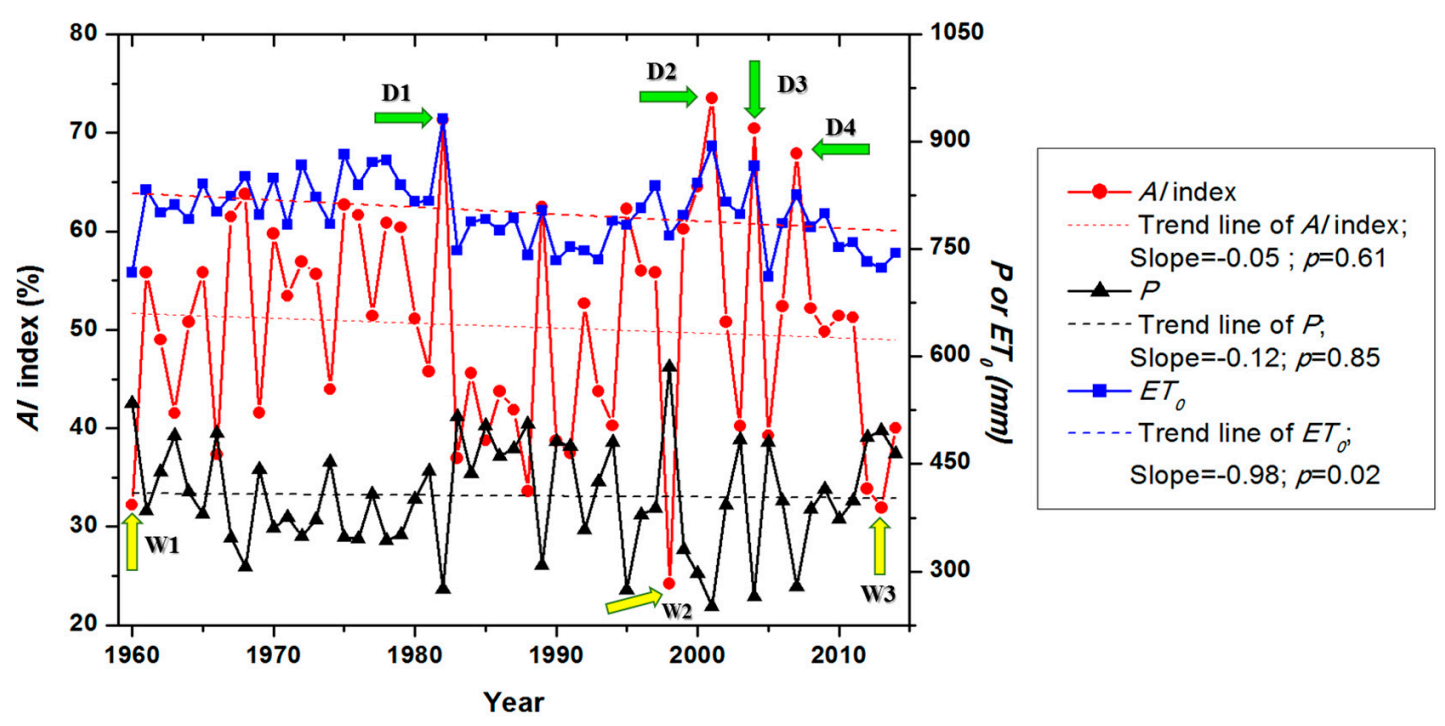

Figure 9. Comparison of the temporal trend of $E T_{0}, A I$, and $P$ during 1960-2014. D, the drought year; $\mathrm{W}$, the wet year. The slopes are examined by linear regression.

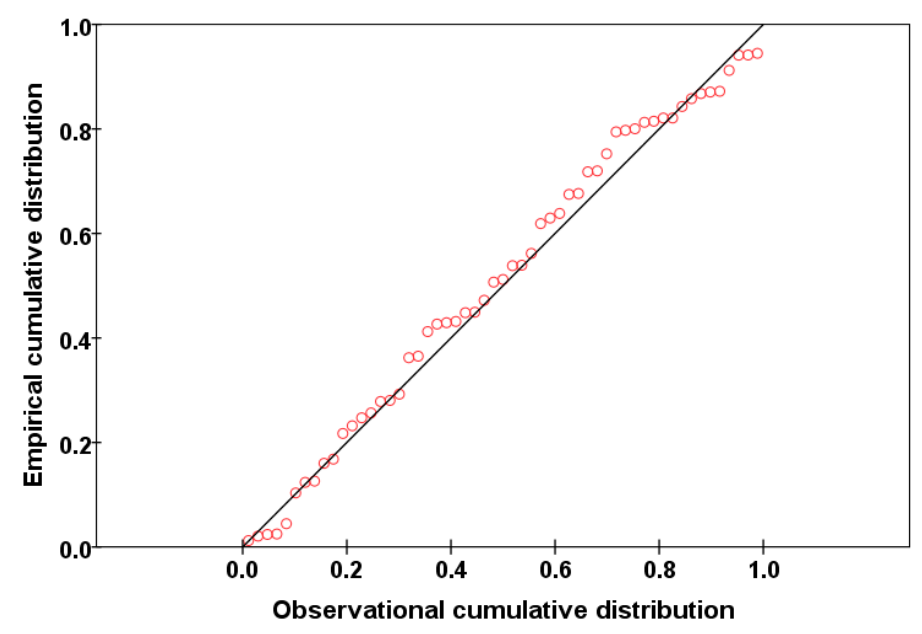

Figure 10. P-P plot of the regression residual standard error for $E T_{0}, A I$, and $P$. 


\section{Discussion}

The Songnen Grassland shows obvious spatial variations of $E T_{0}$ rates from the northeast to southwest at different time scales (Figure 2). These variations are influenced by different regional climates and local topography. In the northeast and east, the temperature is comparatively low, because there were some valleys and the stations were located in a relatively high latitude area combined with the cold temperate continental monsoon climate, leading to the lower values of $E T_{0}$ in these areas; while in the southwest, the topography was relatively flat at lower latitudes (Figure 1), in addition to being far away from the ocean, resulting in the lower relative humidity and the higher values of $E T_{0}$. Moreover, in this study, the IDW method could affect the accuracy of the spatial distribution as well. Previous studies indicated that the interpolation methods should account for external factors, such as altitude and land use patterns [42]. However, compared with other interpolation methods, the IDW produced slightly better predictions of $E T_{0}[29,43]$. Future studies should consider how different interpolation methods impact the spatial variations of $E T_{0}$ at different time scales.

Moreover, the trend analyses of $E T_{0}$ at different time scales by linear regression and non-parametric tests were consistent. Results show that the $E T_{0}$ rates over the Songnen Grassland have been decreasing over the last few decades (Figures 3-5). The results were consistent with decreasing trends in the lower reaches of the Taoer River basin in Northeast China investigated by Liang et al. [30]. Huo et al. [4] also reported a decreasing trend in the arid area of northwest China during 1955-2008. However, as discussed in the introduction, some studies have identified increasing trends in some regions during the last few decades. One of the reasons for the inconsistent findings in $E T_{0}$ trends is due to the fact that some studies on climate change utilize divergent climatic parameters, potentially providing incomplete or artificial trends and magnitudes of $E T_{0}$ [11].

During the study period, the observed variations in Max T, Min T, and Ave $T$ were similar to the global pattern of increasing minimum, mean, and maximum temperature [12]; and the results of the analysis of other climatic factors were consistent with the findings reported from Yunnan Province in southwest China during 1961-2004 [5]. There, the sensitivity analyses for changes in the annual $E T_{0}$ showed that Ave $R H$ and Max $T$ were the most sensitive climate variables over the whole Songnen Grassland, which was in agreement with Yin et al. [44], who studied all of China during 1961-2008. However, Liu et al. [14] has reported that Win $S$ and Sun $H$ were the most sensitive factors in other parts of China. Therefore, it can be concluded that $E T_{0}$ has different responses to climate variables in different regions and under different climate conditions. The reasons for the inconsistent responses of $E T_{0}$ may be the geographical position (e.g., distance from the ocean, the altitude variations) and the research period. In addition, this study indicates that the increase of $E T_{0}$ induced by rising air temperature can be compensated by the reduced $E T_{0}$ with the significant decrease of Ave $R H$, Win $S$, and Sun $H$. As a result, the regional $E T_{0}$ appeared to show a declining trend. Human activity could account for some of the local climate change [36], such as greenhouse gas (GHG) emissions and rapid urbanization, which should be further studied in the Songnen Grassland. In addition, the existence of natural climate variability may also affect the $E T_{0}$ trends. Further research should focus on how to identify the effect of climate natural variability in the changes of $E T_{0}$, for better understanding of the mechanism of $E T_{0}$ variations.

Comparing the results of the detected change points of $E T_{0}$ with the climatic factors in the annual time scale during 1960-2014, abrupt changes were detected in 1989, 1994, and 2009, while the most sensitive factors, Ave RH and Max T, were detected in 1993 and 1989. There is a good correspondence between these two sensitive factors and the $E T_{0}$ series. However, undoubtedly, the abrupt change of other climate factors also played an important role in the abrupt changes of $E T_{0}$. From 1989 to 1994 , the $E T_{0}$ experienced an abrupt decreasing trend due to the abrupt increasing trend of Max $T$, Min $T$, and Ave $T$, and decreasing trend of Sun $H$ and Win $S$; the Ave RH also experienced an increasing trend until it reached the year of abrupt change in 1993. From 1994 to 2009, the $E T_{0}$ experienced an abrupt increasing trend arising from the abrupt increasing trend of Max $T$, Min $T$, and Ave $T$, and the decreasing trend of Ave $R H$, Sun $H$, and Win $S$. After 2009, the temporal trend of $E T_{0}$ decreased 
again, although no change points of the climate factors were detected. This can be due to, as shown in Figure 3, the decreasing trends of every climate parameter except for the Ave $R H$.

As a whole, the abrupt changes of $E T_{0}$ and its related climatic factors mainly occurred in the early and mid-1990s, and it may be concluded that climate variations were more dramatic since this period, when the air temperature remarkably increased, with decreasing trends of Ave $R H$, Win $S$, and Sun $H$. This period of abrupt surface warming was consistent with Dong et al. [45], who reported an abrupt increase in summer mean surface air temperature over Northeast Asia since the mid-1990s. Accompanying the above mentioned climatic anomalies, a decrease in $E T_{0}$ in the Songnen Grassland was observed. In addition, previous studies indicated that the northeast China climate is affected by both the thermal contrast between the Asian continent and the tropical Indo-Pacific Oceans and that between the continent and the extratropical North Pacific [46]. The western Pacific subtropical high (significant positive correlation with summer temperature at the 0.05 level during 1994-2012), zonal circulation (same as above), and Arctic Oscillation (high positive correlation with winter temperature during 1951-1999) also have strong correlations with regional climate variations over northeast China $[47,48]$. The temperature is one of the most sensitive factors for the change in $E T_{0}$, therefore, the large-scale atmospheric and ocean circulation may be other reasons for the abrupt change and variations in $E T_{0}$. Future studies should be focused on these effects on the changes in $E T_{0}$ in the Songnen Grassland.

$E T_{0}$ variations and its response to regional dry/wet conditions are of great importance for crop growing and natural vegetation $[3,49]$. For this purpose, the present study analyzed the long term variations of $E T_{0}, A I$, and $P$ for the growing season during 1960-2014. The results showed that $E T_{0}$ and $A I$ decreased as the $P$ increased, especially during drought or wet years and vice versa (Figure 10). This was consistent with Madhu et al. [33], who reported that higher ET values were detected in the moderate and severe droughts years. It could be inferred from Equation (6) that $A I$ has a positive correlation with $E T_{0}$ and a negative correlation with $P$. The correlation was analyzed by the Pearson correlation analysis, and the results showed that $A I$ has a significant positive correlation with $E T_{0}$ $(r=0.766, p=0.00)$, and it has a significant negative correlation with $P(r=-0.977, p=0.00)$. Figure 9 shows that all the trends of $E T_{0}, A I$, and $P$ were decreasing during the growing season from 1960-2014, and the decreasing rate of $E T_{0}$ was higher than that of $P$. Thus, with the significant decreasing trend of $E T_{0}$, the climate in the Songnen Grassland became slightly wetter from 1960-2014, and the trend will be continued if the decreasing trend of $E T_{0}$ and no obvious change of precipitation persists. In short, under the decreasing $E T_{0}$ conditions, agricultural and ecological water requirements will decrease, especially during the growing season, and agriculture irrigation water requirements will reduce as well. These could have a positive influence for vegetation growth, agricultural production, and ecology.

\section{Conclusions}

In this study, the spatial distributions of $E T_{0}, P$, and their difference were obtained at different time scales. The temporal and spatial variations of $E T_{0}$ were determined for 55 years of data from 21 stations in and around the Songnen Grassland, northeast China, during 1960-2014. The interannual variability of climatic variables was investigated during the study period, and a sensitivity analysis was conducted. The role of $E T_{0}$ in regional dry/wet conditions was discussed based on the analysis of the relationship between $E T_{0}, P$, and $A I$. The following conclusions can be drawn from this study.

(1) The trend analysis of $E T_{0}$ at different time scales shows an evident decreasing trend over the last 55 years, especially in the annual and spring periods. A break trend analysis shows that almost all considered climatological normal periods had experienced the decreasing trend, with a range of -2.415 to $-0.003 \mathrm{~mm}$ per year. Abrupt changes were mainly detected in the early and mid-1990s in the annual, seasonal, and the growing season time series of $E T_{0}$.

(2) The spatial distributions of $E T_{0}$ increased from the northeast to southwest in the annual, seasonal, and the growing season time series during 1960-2014. The spatial variations of $E T_{0}$ indicated that 
the most significant decreasing trends were distributed in the eastern, northeastern, and central regions during the annual, spring, and growing season periods.

(3) The interannual variability of climatic parameters indicated that the annual Max $T$, Ave $T$, and Min $T$ displayed significant increasing trends at the 0.05 level (one-sided $t$-test), and significant decreasing trends were found for Ave $R H$, Win $S$, and Sun $H$. Ave $R H$ was the dominant climate variable for the declining annual $E T_{0}$ over the entire region, with the sensitivity decreasing from Max $T$, Win $S$, Sun $H$, Min $T$, to Ave $T$. Abrupt changes were detected in the annual time series of these variable; Ave $R H$ in 1993, Max $T$ in 1989, Win $S$ in 1990, Sun $H$ in 1987, Min $T$ in 1983, and Ave $T$ in 1987.

(4) In general, the results of this study indicate that the regional drought/wetness condition became mildly wetter with decreasing $E T_{0}$ during the growing season in the last 55 years. Regional climate drought has been alleviated in recent decades. These findings can serve as a reference for policy-makers for better planning and efficient use of agricultural water resources in the Songnen Grassland.

Acknowledgments: This study was financially supported by the National Key Technology R\&D Program of China under Grant Nos. 2013BAK05B02 and 2013ВАК05B01. The authors are grateful to the anonymous reviewers for their insightful and constructive comments for improving this manuscript.

Author Contributions: Jiquan Zhang was responsible for the original idea of the study; Caiyun Sun and Enliang Guo were responsible for the data compilation; Feng Zhang and Mengmeng Wang were responsible for the data processing and drawing; Qiyun Ma drafted the manuscript and all authors read and revised the final manuscript.

Conflicts of Interest: The authors declare no conflict of interest.

\section{References}

1. Stephens, G.L.; Hu, Y.X. Are climate-related changes to the character of global-mean precipitation predictable? Environ. Res. Lett. 2010, 5, 025209. [CrossRef]

2. Escribano Frances, G.; Quevauviller, P.; San Martin Gonzalez, E.; Vargas Amelin, E. Climate change policy and water resources in the EU and Spain. A closer look into the Water Framework Directive. Environ. Sci. Policy 2017, 69, 1-12. [CrossRef]

3. Croitoru, A.; Piticar, A.; Dragotă, C.S.; Burada, D.C. Recent changes in reference evapotranspiration in Romania. Glob. Planet. Chang. 2013, 111, 127-136. [CrossRef]

4. Huo, Z.; Dai, X.; Feng, S.; Kang, S.; Huang, G. Effect of climate change on reference evapotranspiration and aridity index in arid region of China. J. Hydrol. 2013, 492, 24-34. [CrossRef]

5. Fan, Z.; Thomas, A. Spatiotemporal variability of reference evapotranspiration and its contributing climatic factors in Yunnan Province, SW China, 1961-2004. Clim. Chang. 2013, 116, 309-325. [CrossRef]

6. Lu, J.; Zhang, G.; Wu, F. Web-based Multi-Criteria Group Decision Support System with Linguistic Term Processing Function. IEEE Intell. Inform. Bull. 2005, 5, 35-43.

7. Naderpour, M.; Lu, J.; Zhang, G. An intelligent situation awareness support system for safety-critical environments. Decis. Support Syst. 2014, 59, 325-340. [CrossRef]

8. Shadmani, M.; Marofi, S.; Roknian, M. Trend Analysis in Reference Evapotranspiration Using Mann-Kendall and Spearman's Rho Tests in Arid Regions of Iran. Water Resour. Manag. 2012, 26, 211-224. [CrossRef]

9. Tabari, H.; Aghajanloo, M.B. Temporal pattern of aridity index in Iran with considering precipitation and evapotranspiration trends. Int. J. Clim. 2013, 33, 396-409. [CrossRef]

10. Wang, Y.; Jiang, T.; Bothe, O.; Fraedrich, K. Changes of pan evaporation and reference evapotranspiration in the Yangtze River basin. Theor. Appl. Climatol. 2007, 90, 13-23. [CrossRef]

11. Irmak, S.; Kabenge, I.; Skaggs, K.E.; Mutiibwa, D. Trend and magnitude of changes in climate variables and reference evapotranspiration over 116-yr period in the Platte River Basin, central Nebraska-USA. J. Hydrol. 2012, 420-421, 228-244. [CrossRef]

12. Roderick, M.L.; Farquhar, G.D. Changes in New Zealand pan evaporation since the 1970s. Int. J. Climatol. 2005, 25, 2031-2039. [CrossRef]

13. Bandyopadhyay, A.; Bhadra, A.; Raghuwanshi, N.S.; Singh, R. Temporal trends in estimates of reference evapotranspiration over India. J. Hydrol. Eng. 2009, 14, 508-515. [CrossRef] 
14. Liu, T.; Li, L.; Lai, J.; Liu, C.; Zhuang, W. Reference evapotranspiration change and its sensitivity to climate variables in southwest China. Theor. Appl. Climatol. 2016, 125, 1-10. [CrossRef]

15. Dinpashoh, Y.; Jhajharia, D.; Fakheri-Fard, A.; Singh, V.P.; Kahya, E. Trends in reference crop evapotranspiration over Iran. J. Hydrol. 2011, 375, 65-77. [CrossRef]

16. Liu, Y.; Zhuang, Q.; Pan, Z.; Miralles, D.; Tchebakova, N.; Kicklighter, D.; Chen, J.; Sirin, A.; He, Y.; Zhou, G.; et al. Response of evapotranspiration and water availability to the changing climate in Northern Eurasia. Clim. Chang. 2014, 126, 413-427. [CrossRef]

17. Zheng, S.; Qin, Z.; Zhang, W. Drought variation in Songnen Plain and its response to climate change. Chin. J. Agrometeorol. 2015, 36, 640-649.

18. Zhang, Y.; Deng, J.; Guan, D.; Jin, C.; Wang, A.; Wu, J.; Yuan, F. Spatiotemporal changes of potential evapotranspiration in Songnen Plain of Northeast China. Chin. J. Appl. Ecol. 2011, 22, 1702-1710.

19. Limin, S.G.; Oue, H.; Takase, K. Estimation of areal average rainfall in the mountainous Kamo River Watershed, Japan. J. Agric. Meteorol. 2015, 71, 90-97. [CrossRef]

20. Allen, R.G.; Pereira, L.S.; Raes, D.; Smith, M. Crop Evapotranspiration-Guidelines for Computing Crop Water Requirements_FAO Irrigation and Drainage; FAO: Rome, Italy, 1998; p. 56.

21. Mosaedi, A.; Sough, M.G.; Sadeghi, S.; Mooshakhian, Y.; Bannayan, M. Sensitivity analysis of monthly reference crop evapotranspiration trends in Iran: A qualitative approach. Theor. Appl. Climatol. 2017, 128, 857-873. [CrossRef]

22. Liu, C.; Zhang, D.; Liu, X.; Zhao, C. Spatial and temporal change in the potential evapotranspiration sensitivity to meteorological factors in China (1960-2007). J. Geogr. Sci. 2012, 22, 3-14. [CrossRef]

23. Kendall, M.G. Rank Correlation Methods; Griffin: London, UK, 1948.

24. Mann, H.B. Nonparametric tests against trend. Econometrica 1945, 13, 245-259. [CrossRef]

25. Wang, W.; Zhu, Y.; Xu, R.; Liu, J. Drought severity change in China during 1961-2012 indicated by SPI and SPEI. Nat. Hazards 2015, 75, 2437-2451. [CrossRef]

26. Zhang, Q.; Zhang, J. Drought hazard assessment in typical corn cultivated areas of China at present and potential climate change. Nat. Hazards 2016, 81, 1323-1331. [CrossRef]

27. Yan, T.; Shen, Z.; Bai, J. Spatial and temporal changes in temperature, precipitation, and streamflow in the Miyun Reservoir Basin of China. Water 2017, 9, 78. [CrossRef]

28. Tabari, H.; Taye, M.T.; Willems, P. Statistical assessment of precipitation trends in the upper Blue Nile River basin. Stoch. Environ. Res. Risk Assess. 2015, 29, 1751-1961. [CrossRef]

29. Palizdan, N.; Falamarzi, Y.; Huang, Y.F.; Lee, T.S. Precipitation trend analysis using discrete wavelet transform at the Langat River Basin, Selangor, Malaysia. Stoch. Environ. Res. Risk Assess. 2017, 31, 853-877. [CrossRef]

30. Liang, L.; Li, L.; Liu, Q. Temporal variation of reference evapotranspiration during 1961-2005 in the Taoer River basin of Northeast China. Agric. For. Meteorol. 2010, 150, 298-306. [CrossRef]

31. Sen, P.K. Estimates of the regression coefficient based on Kendall's tau. J. Am. Stat. Assoc. 1968, 63, 1379-1389. [CrossRef]

32. Salmi, T.; Maatta, A.; Anttila, P.; Ruoho-Airola, T.; Amnell, T. Detecting Trends of Annual Values of Atmospheric Pollutants by the Mann-Kendall Test and Sen's Slope Estimates-The Excel Template Application MAKESENS; Publications on Air Quality 31; Report Code FMIAQ-31; Universitas Gadjah Mada: Yogyakarta, The Republic of Indonesia, 2002.

33. Madhu, S.; Kumar, T.V.L.; Barbosa, H.; Rao, K.K.; Bhaskar, V.V. Trend analysis of evapotranspiration and its response to droughts over India. Theor. Appl. Climatol. 2015, 121, 41-51. [CrossRef]

34. Arguez, A.; Vose, R.S. The Definition of the Standard WMO Climate Normal: The Key to Deriving Alternative Climate Normals. Bull. Am. Meteorol. Soc. 2011, 92, 699-704. [CrossRef]

35. Zhao, L.; Xia, J.; Sobkowiak, L.; Li, Z. Climatic characteristics of reference evapotranspiration in the Hai River Basin and their attribution. Water 2014, 6, 1482-1499. [CrossRef]

36. Zheng, C.; Wang, Q. Spatiotemporal pattern of the global sensitivity of the reference evapotranspiration to climatic variables in recent five decades over China. Stoch. Environ. Res. Risk. Assess. 2015, 29, 1937-1947. [CrossRef]

37. Zhan, X.; Kustas, W.P.; Humes, K.S. An intercomparison study on models of sensible heat flux over partial canopy surfaces with remotely sensed surface temperature. Remote Sens. Environ. 1996, 58, 242-256. [CrossRef]

38. Su, X.; Singh, V.P.; Niu, J.; Hao, L. Spatiotemporal trends of aridity index in Shiyang River basin of northwest China. Stoch. Environ. Res. Risk. Assess. 2015, 29, 1571-1582. [CrossRef] 
39. Thornthwaite, C.W. An approach toward a rational classification of climate. Geogr. Rev. 1948, 38, 55-89. [CrossRef]

40. Zhang, K.; Pan, S.; Zhang, W.; Xu, Y.; Cao, L.; Hao, Y.; Wang, Y. Influence of climate change on reference evapotranspiration and aridity index and their temporal-spatial variations in the Yellow River Basin, China, from 1961 to 2012. Quat. Int. 2015, 380-381, 75-82. [CrossRef]

41. Ashraf, M.; Routray, J.K. Spatio-temporal characteristics of precipitation and drought in Balochistan Province, Pakistan. Nat. Hazards 2015, 77, 229-254. [CrossRef]

42. Li, X.; Gemmer, M.; Zhai, J.; Liu, X.; Su, B.; Wang, Y. Spatio-temporal variation of actual evapotranspiration in the Haihe River Basin of the past 50 years. Quat. Int. 2013, 304, 133-141. [CrossRef]

43. Piticar, A.; Mihăilă, D.; Lazurca, L.G.; Bistricean, P.; Puţuntică, A.; Briciu, A. Spatiotemporal distribution of reference evapotranspiration in the Republic of Moldova. Theor. Appl. Climatol. 2016, 124, 1133-1144. [CrossRef]

44. Yin, Y.; Wu, S.; Chen, G.; Dai, E. Attribution analyses of potential evapotranspiration changes in China since the 1960s. Theor. Appl. Climatol. 2010, 101, 19-28. [CrossRef]

45. Dong, B.; Sutton, R.T.; Chen, W.; Liu, X.; Lu, R.; Sun, Y. Abrupt summer warming and changes in temperature extremes over Northeast Asia since the mid-1990s: Drivers and physical processes. Adv. Atmos. Sci. 2016, 33, 1005-1023. [CrossRef]

46. Liu, S.; Yang, S.; Lian, Y.; Zheng, D.; Wen, M.; Tu, G.; Shen, B.; Gao, Z.; Wang, D. Time-frequency characteristics of regional climate over northeast China and their relationships with atmospheric circulation patterns. J. Clim. 2010, 23, 4956-4972. [CrossRef]

47. Gong, D.Y.; Wang, S.W. Influence of Arctic Oscillation on Winter Climate over China. J. Geogr. Sci. 2003, 13, 208-216.

48. Li, J.; Jiao, M.; Hu, C.; Li, F.; Zhang, X.; Zhang, Q.; Wang, Y.; Zhu, X. Characteristics of summer temperature and its impact factors in Northeast China from 1951 to 2012. J. Meteorol. Environ. 2016, 32, 74-83.

49. Espadafor, M.; Lorite, I.J.; Gavilan, P.; Berengena, J. An analysis of the tendency of reference evapotranspiration estimates and other climate variables during the last 45 years in Southern Spain. Agric. Water Manag. 2011, 98, 1045-1061. [CrossRef]

(C) 2017 by the authors. Licensee MDPI, Basel, Switzerland. This article is an open access article distributed under the terms and conditions of the Creative Commons Attribution (CC BY) license (http:/ / creativecommons.org/licenses/by/4.0/). 